\title{
Thinking of High-Rise Buildings Design
}

\author{
Xiang Feng \\ Department of Architectural Engineering \\ School of Yibin Vocational and Technical College \\ Yibin, Sichuan, China \\ 576565007@qq.com
}

\author{
Yanli Guo \\ Department of Architectural Engineering \\ School of Yibin Vocational and Technical College \\ Yibin, Sichuan, China \\ guoyanli_3356@163.com
}

\begin{abstract}
Based on the architectural modeling and technology, this paper use the design principle of high-rise buildings, describes the structure system problen of the high-rise building structure, the structure idea of plane design in high-rise building, and the structure idea of profile design in high-rise building. And put forward to by using the structural logical thinking, image thinking and creative thinking to design the sustainable development high-rise building.
\end{abstract}

Keywords-High-rise buildings; design; structure thinking; sustainable development

\section{INTRODUCTION}

Along with the fast development of China's economy, the urban population has expanded, the city land increasingly nervous, the construction of high-rise buildings requires a lot. Without a doubt, the high-rise building for a period of time will have very strong vitality. There are many advantages of high-rise buildings, such as managing land; Shorten municipal pipeline; To a certain extent solve the contradiction of the green land and the buildings land; Shorten the distance between the workplace and the residence; Ease the city traffic pressure, etc. But high-rise building with its own shortcomings, such as high cost, additional equipment more, complex arrangement of public transport, difficult structure design, high modelling demanding, variety load handle which difficult to deal with. Therefore, under the premise of the architecture function, the safety structure and affordable, the design of high-rise building should as far as possible to meet convenient, beautiful modelling, etc.

\section{The SignificAnce Of The High-RISE BuILDING} DESIGN

Because of their own factors, the structure stress of high-rise buildings is very complex. Apart from its great deadweight and dignity and service load, the structure stress still have the wind load come from horizontal and earthquake force. The wind load and earthquake force is the main factors of high-rise building structure design. On the other hand, high-rise buildings have large size, diversified internal functional, complex equipment requirement, all of these are led to higher request of high- rise buildings. In the design, if the architectural and structural separated, only consider the aesthetic and use, then the structure are shoehorned into the building space, this thinking way is very against architectural creation.

The famous Italian architect and structural engineer Neve put forward that the architect must be the creator of the bearing elements and the structure scheme which design by him. The key of the problem is how to develop a mechanics consciousness which is indispensable and based on intuitive, and enables designers must understand the structure design, and should achieve a certain depth and breadth. Then, the idea based on physics, mathematics and experience, translate into a kind of extraordinary complex, translate into a look and meanwhile produce sensitive force.

Therefore, the building structure is not isolated, it is closely associated with the rest of the building. The structure should support up the architectural space and should transfer all the role of the building to foundation. The solution of the problem, is not only directly decided to its security and economic, and decided to the great effect brought by the architectural functions, technology and art.

Structure design is considering the structure of the high-rise building and the use requirement. So, first of all, we should analyze the space nature, and then from plane form and profile form to do the comprehensive coordination, and make each space requirements is identical with its corresponding plane, profile and elevation.

\section{HIGH-RISE BUILDING STRUCTURE SYSTEM PROBLEM}

According to the structure material, high-rise building structure system have three kinds of reinforced concrete structure, steel structure and composite structure of concrete and steel. According to the structure system, high-rise building structure system mainly has the frame structure, shear wall structure, the frame shear wall structure, box tube structure, cone tube structure, arms outstretched in structure, suspension structure and giant structure, as shown in figure 1 and figure 2. 


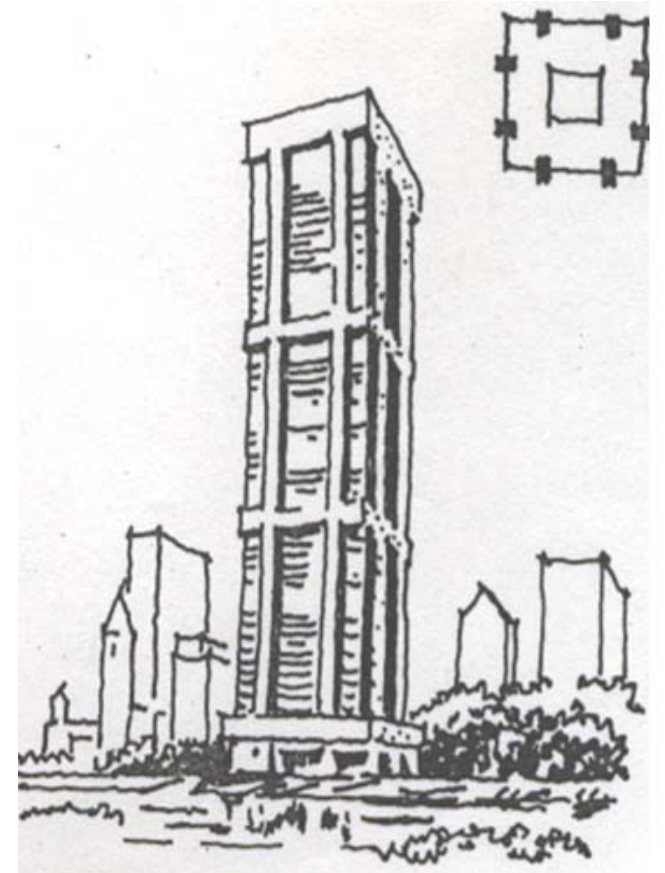

Figure 1. The KaISERBUILding (MEGA FRAME STRUCTURE)

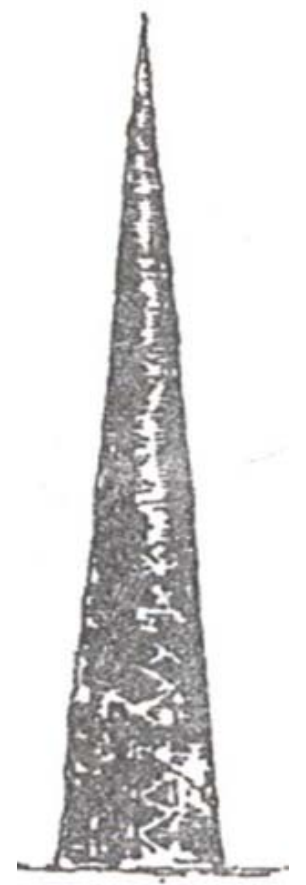

Figure 2. CONICAL STRUCTURE

Composite structures system can give full play to the role of the two kinds of bearing force and their respective advantages within the same building. Such as the One Shell Square Tower Building in New Orleans, which is use the steel reinforced concrete to enhance resist lateral force stiffness, also do improve its fire prevention and insulating heat insulation performance. And as pump strong and high strength concrete into the steel tube can greatly improve the construction speed, shorten the construction period, it will also increase resist lateral force stiffness, save steel consumption. As for the biggest appropriate height of the combination structure, generally more between the similar reinforced concrete structure system and steel structure system. In recent years, the total height of high-rise building is rising, thus appeared some structure system such as arms outstretched structure, hanging structure, mega frame structure and giant truss structure, etc.

In order to reduce the role of the earthquake, in recent years, the engineering examples of suspended structure is appeared. It comes with the advantage of ground floor can form a large space, it can more free to meet the bottom of the building function design. Such as the Colon Building in Spain. Along with the development of the high-rise building, the huge structure is appeared. The giant structure is the development of high-rise building structural. It can not only saving material and can bring greater development and flexibility for building design.

\section{The Structure IdEA OF Plane Design IN High- RISE BUILDING}

\section{A. The Force Characteristic and Plane Form}

There are many factors to influence the plane form of high-rise building, such as terrain, function, environment, and the architect idea of the creation. But, because of the unique force characteristic of high-rise building, it is valuable to analyze the influence to plane form. In horizontal load, the structure of high-rise buildings has the relative lateral, and the whole bending deformation is dominant. The lateral caused by the whole structure bending deformation is inversely proportional to the effective width's cubic of the structural system to resist lateral re-torque. Therefore, strengthen the effective width of the building in plane, it will be able to reduce the relative lateral in a great extent. So, in the form of force, the best form of high-rise building is simple, clean and regulations. A circular building is the best, a square is the second. Though the triangle is the worst,

But after treatment for notch, the effect also can obviously improved. Because the surface area perpendicular to the wind is the minimum in cylindrical building, the wind load can reduce $20 \% \sim 40 \%$ than square shape building. The width along the vertical and horizontal directions of high-rise building, which plane form is round, oval, square, corner cutting triangle and polygon, is

Bigger. It has a good resist lateral stiffness, and the wind area is also less. It is the ideal plane form of high-rise building.

\section{B. The Rationality of Structure Plane Layout}

Based on do not affect the use function of buildings, the plane arrangement of the power transmission components should try to meet the mechanical demand. From the view of mechanical angles, the resist lateral 
structure of high-rise building should as far as possible even decorate, and avoid the migration of horizontal loads center. So, the plane of Marcelo Pizarro Building which designed by Narvi is spindle, both ends of the four triangle wellbore set, the central for the rigid wall. The features of construction model is the same as the resist lateral force structure. The frost building of buildings designed by Wright is windmill form, and make the space and shape broke through the bound of simple geometry. The structure layout is symmetrical ang reasonable.

In practical projects, even if the structure arrangement completely symmetrical, because the quality is hard to distribute even and symmetrical. The centroid is very easy to migrate. When structure arrangement, in addition to requirement symmetry, but also try the best to have greater torsional rigidity. To meet the building function of the premise, change the center arrangement and scattered arrangement of resist lateral force component into around the building or four corners arrangement. So, the wrest resistant ability of the structure has improved greatly.

\section{The Structure Idea of Profile Design IN HIGH-RISE BUILDING}

The profile design is connected with the high-rise buildings form, and the high-rise buildings form is interdependent with the structure system. The artistic of building form must be unity with the rationality of building structure system. Only in this way, the effectiveness of the structure can give full play. So, it is not only to consider and solve the problem of building function, but also use logical thinking and image thinking to conceive the rhythm of architectural space and outline.

Building space form is supported by the structure force transmission. The profile of the structure force transmission form is directly reflect the path of structure transfer load in the vertical direction, and it is related to the use performance of the building also.

First, to control the ratio of building's height and width

In architecture design, with the ratio of building's height and width as the main index of measure the building rigidity and limit the lateral displacement. So, the ratio is bigger, the side torque is bigger. This is bad to building's overall stability. To different structure types, the requirement of the ratio of building's height and width is not the same. The high-rise regulations of China is Stipulate the ratio of building's height and width obviously.

Second, the stiffness of resist lateral force structure is increasingly large from building basic to top

In design, the form of gradually upward raked is very benefic to the structure stress, which can improve the building's whole stiffness, and reduce the lateral. For example, because of the set of the inclined column, the bottom space of the building expand gradually, the stiffness increased by $10 \%$, the ratio of building's height and width is down from 4.48 to 3.6 , the vertices displacement reduced from $71 \mathrm{~mm}$ to $64 \mathrm{~mm}$. With the height increased, the clever design make the building's external support tilt into the internal gradually. And the whole structure system is adapt to the most ideal function layout.

Third, High-rise building must have corresponding anchorage depth

High-rise building must have corresponding anchorage depth. The anchorage depth is general required for $1 / 12$ to $1 / 14$ of building's total height. The higher building height, the bigger anchorage depth. We can reasonable decorate the equipment room and the requirements of the underground parking lot. And we can set a layer or multilayer underground activity space. These is benefic to reduce the building focus, and it can improve the seismic resistance of buildings.

Fourth, the sustainable development of the high-rise building

There are many contradictions between high-rise building and sustainable development, and main show as follows: first, the high-rise building consume more resources, than the same area of multi-storey building; second, the high-rise buildings need to use more energy to ensure its normal operation; third, in case of disaster, the high-rise building is easy to cause great losses, fourth, because of its huge dimension, the high-rise building can cause adverse effects to the city space, sunshine, electromagnetic field, the wind environment and urban landscape; fifth, because of personnel rally, the high-rise building can bring great pressure to urban traffic.

In order to realize the sustainable development in the 21st century, we should promote the development of ecological construction, protect the ecological environment, and create the healthy living environment engineering. The author put forward the following suggestions. First, put the vertical transportation core and the construction hot together. In this way, we can use floor elevator and natural lighting to make the work area has the same temperature and humidity with external. Second, we should treat the indoor air ventilation and sunshine intervention strictly to improve the environmental comfort. Generally, we set a central hall, which can achieve the requirements above. Third, improve plant into high-rise building can improve the vertical landscape, in this process, we should pay attention to the temperature, humidity, sunshine and ventilate. Fourth, use the adjustable exterior wall can make buildings adapt to various climate, and reduce energy consumption. So, the sustainable development concept of high-rise building is to demonstrate the new fashion of residential environment in the 21st century, and it is accord with the development requirement of the human society.

\section{CONCLUSION}

Architecture design is finally to how to improve the design quality in limited conditions, how to create beautiful living environment, and how to contente people's complex requirements to live life for the purpose. This paper presents that the structure system problen of the high-rise building structure, the structure idea of plane design in high-rise building, and the structure idea of profile design in high-rise building. And put forward to by 
using the structural logical thinking, image thinking and creative thinking to design the sustainable development high-rise building.

\section{REFERENCES}

[1] WANG Xi-bin. Strategy research on the integration of architecture design and technology curriculum[J]. Henan Science \& Technology, 2011(6).
[2] QIU Bai-yu. The architecture design of the high-rise building[J]. Building Materials Development Orientation, 2011(6).

[3] SUN Wen-min. The green ecological architecture view of architecture design[J]. Guangdong Science \& Technology, 2011(8).

[4] ZHOU Feng-jun, LI Bing. The application of people-oriented thoughts in modern architectural design[J]. Architectural Design Management, 2010(1).

[5] ZHANG Zhao-min. Modern urban planning and design[M]. Press of China's city university, 2009. 